\title{
Study on Histocompatibility and Biodegradability of Polylactic Acid Gel in Rats
}

\author{
Ting WANG ${ }^{a}$, Pei-Ling CAI ${ }^{b}$, Xin HENG, Li-Jia CHENG ${ }^{*}, c$ \\ School of Medicine and Nursing, Chengdu University, \# 1, Shi-Ling Street, Cheng-Luo Avenue, \\ Chengdu, Sichuan,610106 \\ avioletwt@qq.com, bcaipeiling@cdu.edu.cn, ${ }^{c}$ chenglijia@cdu.edu.cn \\ ${ }^{*}$ Corresponding author
}

Key words: Polylactic Acid Gel, histocompatibility, Biodegradability, Postoperative Adhesions.

\begin{abstract}
Objective: To investigatethe effects on histocompatibility and biodegradability of bioabsorbablepolylacticacid (PLA) gelin rats. Methods: Longitudinal incision of $30 \mathrm{~mm}$ was made along the spine, and subcutaneous tissues were separated bluntly to make four subcutaneous pouches, and PLA gel of different molecular weight $(5,10$ and $20 \mathrm{kD})$ was implanted into the pouches. 4, 7, 11 and 14 weeks after implantation, the samples and surrounding tissues were collected to perform HE staining; meanwhile, the samples were weighted and compared after drying. Results: There were few inflammatory cells accumulations in tissues treated with different molecular weight PLA gel. The degradation rate of $5 \mathrm{kD}$-PLA gel was faster than other groups. With increase of the molecular weight of PLA gel, the degradation rate was gradually decreased. Conclusion: Our findings indicated that PLA gel had good biocompatibility and a definite degrading effect, which could be further used in surgery.
\end{abstract}

\section{Introduction}

The adhesion between tissues and organs is a big trouble in surgical field. The incidence of adhesions was more than $90 \%$ after laparotomy, although early peritoneal adhesions were beneficial for wound healing, the peritoneal adhesions could cause serious complications, such as intestinal obstruction, abdominal pain, female infertility and pelvic pain, which increased the difficulty of surgery ${ }^{[1-3]}$.Therefore, prevention of adhesions is a major problem in surgical field. Polylactic acid (PLA) gel is the polymer product which is made of PLA, it has good biocompatibility and biodegradability $^{[4,5]}$. PLA gel could form films rapidly when wet, then be attached to wound to prevent tissue adhesion without suture, eventually degraded in vivo; which could be used to prevent postoperative adhesions ${ }^{[6]}$. At present, studies focused on improvement of effects of PLA gel ${ }^{[7,8]}$, and the histocompatibility and biodegradability of PLA gel were rarely reported ${ }^{[4,5]}$. In our study, we will investigate the histocompatibility and biodegradability of PLA gel in Sprague Dawley (SD) rats.

\section{Materials and methods}

\section{PLA gel Preparation}

Under sterile conditions, the polylactic acid hydrogel were tiled on one glass disk with $90 \mathrm{~mm}$ diameter, then were sprayed sterile water to form gel film. After natural drying, the film was made into diameter of $8.5 \mathrm{~mm}$, thickness of $0.3 \mathrm{~mm}$ with puncher. Then $2 \mathrm{ml}$ PLA gelwith 95\% purity were placed in tube, and numbered 1, 2, 3 and 4. In which the molecular weight of the No. 1, 2, 3 were $5 \mathrm{kD}, 10 \mathrm{kD}$, and $20 \mathrm{kD}$, and No. 4 was polylactic acid film reference substance.

\section{Animal Surgery}

Thirty two female SD rats $(300 \pm 25 \mathrm{~g})$ were provided by the Centers for Disease Control, Sichuan Province. Animals were anesthetized by intraperitoneal injection of $40 \mathrm{mg} / \mathrm{kg}$ sodium pentobarbital, then the limbs were fixed under the posture of back up; after skin preparation, longitudinal incision 
of $30 \mathrm{~mm}$ was made along the spine, and subcutaneous tissues were separated bluntly to make four subcutaneous pouches. Four PLA gel samples were implanted into subcutaneous pouch, respectively, and the distance between each sample was more than $20 \mathrm{~mm}$. At last, the skin was sutured, and antibiotics were injected to prevent infection. All animals were conventional breed under SPF conditions.

\section{Histocompatibility and Degradability Observation}

4, 7, 11 and 14 weeks after implantation, all animals were killed and samples were harvested. Some samples were fixed in $4 \%$ paraformaldehyde and paraffin-embedded, then the sections were performed $\mathrm{HE}$ staining and the histocompatibility was observed under microscope. The other samples were dried at $70^{\circ} \mathrm{C}$ for $2 \mathrm{~h}$, then weighed using a $1 / 10000$ precision balance.

\section{Statistical Analysis}

All data were expressed as mean \pm standard deviation $(x \pm \mathrm{s})$ and analyzed with Student $\mathrm{T}$ test (SPSS17.0, USA). A $P<0.05$ was considered as statistically significant.

\section{Results}

\section{Histocompatibility of PLA gel}
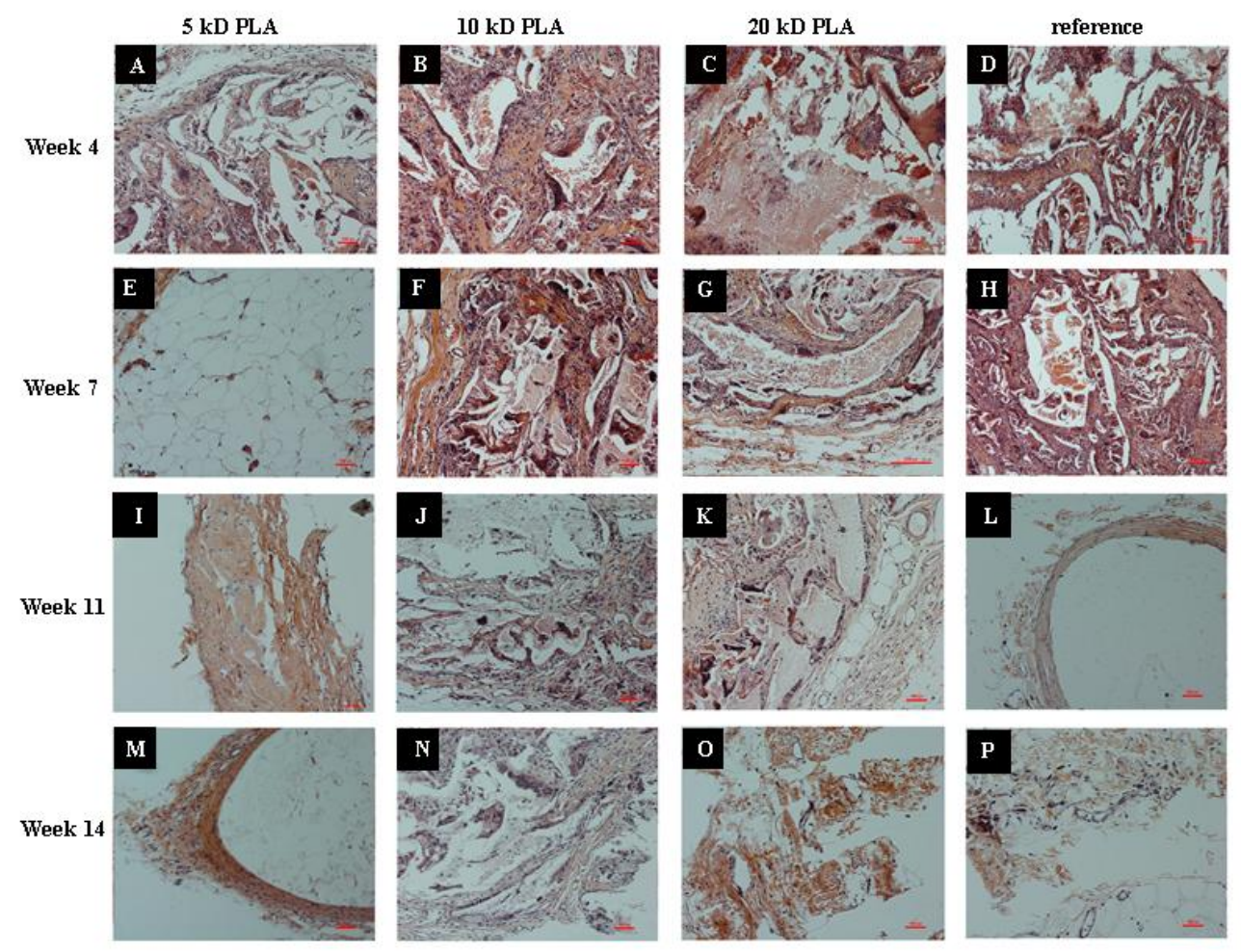

Fig. 1 HE staining showed 4, 7, 11 and 14 weeks after PLA gel implantation. A, E, I, M: No.1 sample, 5 kD PLA gel; B, F, J, N: No. 2 sample, 10 kD PLA gel; C, G, K, O: No.3 sample, 20 kD PLA gel; D, H, L, P: PLA gel film reference substance. Bar: $100 \mu \mathrm{m}$.

Four weeks after implantation, lots of fibroblasts were observed in PLA gel, there were few inflammatory cells. Seven weeks after surgery, there was a dense fiber wrapped around materials in all the four groups. In No.1 PLA gel, the adipocytes aggregated in fiber capsule; other groups showed a large number of fibroblasts which split wrapped the materials. At the $11^{\text {th }}$ week, the fibrous capsule cavity wall was formed, and the adipocyte aggregation appeared in the fibrous capsule in NO.4 PLA gel. At the $14^{\text {th }}$ week, the fibrous capsule wall showed relaxation, and the un-degraded residue materials showed graininess which were wrapped by fibroblasts (Figure 1). 
The results revealed all the PLA gel of $5 \mathrm{kD}, 10 \mathrm{kD}$ and $20 \mathrm{kD}$ had good histocompatibility, since there were few inflammatory cells and other side effects in the four groups.

\section{Biodegradability of PLA gel}

Seven weeks after implantation, No.1 PLA gel showed obvious pimelosis. At the $11^{\text {th }}$ week, No.1 PLA gel and PLA gel film reference substance appeared significant pimelosis. At the $14^{\text {th }}$ week, all samples had pimelosis at different degree and frangibility in the four groups (Figure 2). The weight changes were shown in Table 1 . The results showed that the degradation rate of $5 \mathrm{kD}$-PLA gel was faster than other groups. With increase of the molecular weight of PLA gel, the degradation rate was gradually decreased.

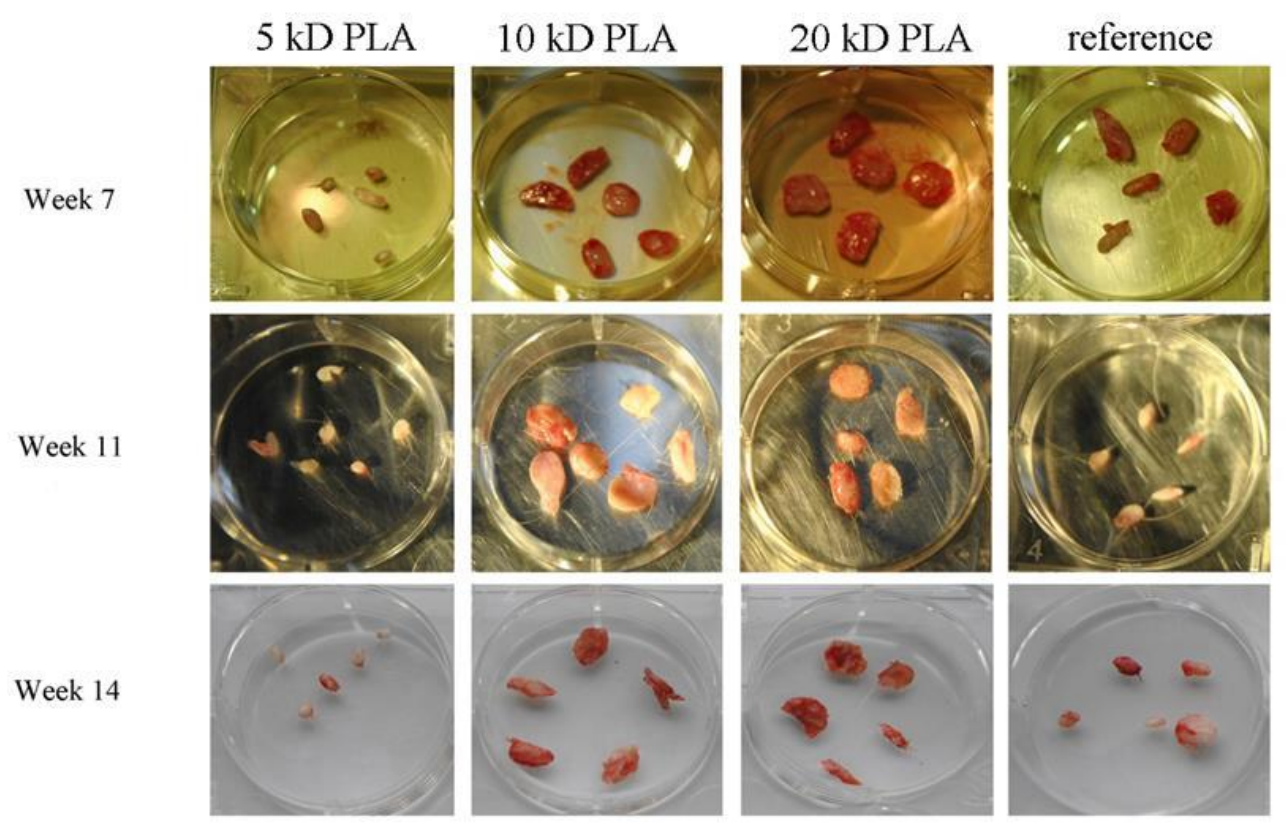

Fig. 2 The morphology observation of PLA gel with different molecular weight at week 7, 11 and 14

\section{Discussion}

Our study showed that there were only a few inflammatory cells in PLA gel with 5, 10 and $20 \mathrm{kD}$ molecular weight implanted in rats, indicating that the PLA gel with different molecular weight have good biocompatibility. In addition, the degradation rate was increased with the decrease of molecular weight of PLA gel. At week 7, all samples appeared pimelosis, which had been mostly degraded in $5 \mathrm{kD}-\mathrm{PLA}$ gel. However, the degradation rate was slower in $10 \mathrm{kD}-\mathrm{PLA}$ gel and 20 $\mathrm{kD}$-PLA gel, in which there were still residual materials at week 14. As for the PLA gel film reference substance, the degradation rate was slightly lower than that of No.1, the materials had been absorbed and degraded and only cellulite was observed at week 14. The degradation rateof PLA gel with different molecular weight was consistent with previous studies ${ }^{[9,10]}$. Clinically, the degradation rate of PLA gel materials needed to match with the time of wound healing ${ }^{[11,12]}$; therefore, we could chose different molecular weight of PLA gel according to the operative positions and tissue regeneration ability, which couldcontrol the degradation rate of PLA gel to get the maximized effect of wound protection.

\section{Acknowledgments}

This research was supported by National Natural Science Foundation of China (No. 51402027) and Natural Science Foundation of Chengdu University (No.2014XJZ01 and No.2011XJZ14). 


\section{Conflict of Interests}

The authors declare that there is no conflict of interests regarding the publication of this article.

\section{References}

[1] van der Wal JB, Iordens GI, Vrijland WW, et al. Adhesion prevention during laparotomy: long-term follow-up of a randomized clinical trial. Ann Surg. 2011; 253(6):1118-21.

[2] Wallwiener M, Koninckx PR, Hackethal A, et al. A European survey on awareness of post-surgical adhesions among gynaecological surgeons.Gynecol Surg. 2014; 11: 105-112.

[3] Banasiewicz T, Horbacka K, Karoń J, et al. Preliminary study with SprayShield ${ }^{\mathrm{TM}}$ Adhesion Barrier System in the prevention of abdominal adhesions. WideochirInne Tech MaloInwazyjne. 2013; 8(4):301-9.

[4] Flege C, Vogt F, Höges S, et al. Development and characterization of a coronary polylactic acid stent prototype generated by selective laser melting. J Mater Sci Mater Med. 2013;24(1):241-55.

[5] Wu CS. Characterizing biodegradation of PLA and PLA-g-AA/starch films using a phosphate-solubilizing bacillus species.MacromolBiosci. 2008; 8(6):560-7.

[6] Chuang JP, Chang CP, Shen HT, et al. Repair of the canine vertebral lamina with a combination of autologous micromorselized bone and poly-lactic acid gel after a total laminectomy. Kaohsiung $\mathrm{J}$ Med Sci. 2010;26(7):357-65.

[7] Li BC, Jiao SS, Xu C, et al. PLGA conduit seeded with olfactory ensheathing cells for bridging sciatic nerve defect of rats. J Biomed Mater Res A. 2010; 94(3):769-80.

[8] Schoenhammer K, Petersen H, Guethlein F, Goepferich A. Injectable in situ forming depot systems: PEG-DAE as novel solvent for improved PLGA storage stability. Int J Pharm. 2009; 371(1-2): 33-9.

[9] Odelius K, Höglund A, Kumar S, et al. Porosity and pore size regulate the degradation product profile of polylactide. Biomacromolecules. 2011; 12(4): 1250-8.

[10] Qu XH, Wu Q, Zhang KY, Chen GQ. In vivo studies of poly(3-hydroxybutyrate-co-3-hydroxyhexanoate) based polymers: biodegradation and tissue reactions. Biomaterials. 2006; 27(19): 3540-8.

[11] Tschon M, Fini M, Giavaresi G, et al. In vitro and in vivo behaviour of biodegradable and injectable PLA/PGA copolymers related to different matrices. Int $\mathrm{J}$ Artif Organs. 2007; 30(4):352-62.

[12] Chen G, Liu T. Therapeutic evaluation of the polylactic acid gel (PLA-G) used for preventing skin flap adhesion in modified radical mastectomy. Sheng Wu Yi Xue Gong Cheng XueZaZhi. 2013; 30(6):1276-8. 